\title{
A idealização da natureza, do imaginado ao comemorado: os processos de simbolização em narrativas da identidade rural goiana
}

\author{
The idealization of nature, imagined by celebrated: the processes of \\ symbolization of identity narratives in rural Goiás
}

\author{
Maria Francisca Magalhães Nogueira \\ (mfrancisnogueira@gmail.com) \\ Margarida Maria Cavalcanti Limena ${ }^{2}$ \\ (mfrancisnogueira@gmail.com) \\ Daniel Christino ${ }^{3}$ \\ (dchristino@gmail.com)
}

\begin{abstract}
Resumo
Pesquisa sobre o imaginário rural de Goiás em que objetiva estudar e compreender as motivações que levam o indivíduo a buscar o campo como espaço de lazer e sociabilidade, num estado no qual, culturalmente, predomina as características rurais. Inicialmente, levantou-se aspectos históricos com fins de reconstituir o que de fato existiu no imaginário rural da sociedade goiana através de autores reconhecidos. A seguir, realizou-se entrevistas aleatórias com turistas rurais, que na sua maioria tratava-se de turistas de origem rural, em decorrência da predominância do status rural existente no estado. A análise dos dados evidencia a predominância do status rural no estado, porém percebe-se mudanças na re-elaboração simbólica do rural tradicional. Conclui-se que o imaginário rural goiano está repleto de símbolos originados da tradição rural de Goiás, embora esteja em construção novos re-significados, reflexos de um passado agregado à memória coletiva.
\end{abstract}

Palavras-chave: Imaginário rural goiano. Turismo rural goiano. Sociabilidade.

\begin{abstract}
Research on Goiás's rural imagery of which aims to study and understand the motivations that lead the individual to pursue the countryside as a place of leisure and sociability, a state in which, culturally, rural characteristics predominate. Initially, it focuses on historical aspects with the purpose of reconstructing what actually existed in the imagination of the rural society from Goiás through recognized authors. The following interviews were performed with random rural tourists, whose mostly were tourists from rural areas, due to the predominance of existence of a rural status in the state. Data analysis shows the predominance of rural status in the state, but it is perceived changes in the re-establishment of the traditional symbolism on rural. We conclude that the Goiás rural imaginary is full of symbols originated from the rural tradition of Goiás, although in rebuilding new meanings, reflections of a past aggregating the collective memory.
\end{abstract}

Keywords: Goiás Rural Imaginary. Goiás Rural tourism. Sociability.

\footnotetext{
${ }^{1}$ Doutora em Ciências Sócias pela PUC/SP. Mestre em Ciências da Comunicação pela ECA/USP. Docente do Programa de PósGraduação em Comunicação e do curso de especialização em Avaliação de Ambientes Informacionais da Universidade Federal de Goiás (UFG). Coordenadora do Grupo de Pesquisa Complexidade e Comunicação da UFG/CNPq.

${ }^{2}$ Doutora em Ciências Sociais. Docente do Programa de Pós-Graduação em Ciências Sociais da Pontifícia Universidade Católica de São Paulo (PUC). Pró-Reitora de Graduação da PUC/SP. Membro do Núcleo de Estudos da Complexidade da PUC/SP.

${ }^{3}$ Doutor em Comunicação Social pela Universidade de Brasília (UNB), docente do Programa de mestrado em comunicação do curso de Comunicação Social da Universidade Federal de Goiás (UFG).
} 


\section{Introdução}

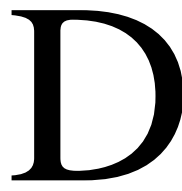
esenvolvemos de agosto a novembro de 2009 pesquisa a fim de compreender as várias e multiformes motivações imaginárias do individuo que busca o campo como espaço de lazer e sociabilidade. O trajeto rumo ao imaginário de rural do turista teve como objetivo captar as significações - as representações, as idéias, os sentimentos associados pelos indivíduos à idéia de campo -, através da vivência direta e intensa do turista em contato com o campo, considerando que as significações sociais se "inscrevem" e se "encarnam" no "mundo sensível", e também pela vivência e eficacidade dos indivíduos. Como nos ensina Morin (1997, p. 42), "a imagem mental é estrutura essencialmente de consciência, função psicológica. Não é possível dissocia-la da presença do mundo do homem, da presença do homem no mundo".

É certo que os turistas não são - e nem mesmo a totalidade dos indivíduos - os suportes que carregariam todas as significações sociais de uma sociedade e, a exemplo, as referentes ao rural. Conforme Castoriadis (1982, p. 411)

não se pode reduzir o mundo de significações instituídas às representações individuais efetivas. Mas é inevitável, e até necessariamente, que uma parte das significações imaginárias sociais encontre um "equivalente" efetivo nos indivíduos (em sua representação consciente ou não, em seu comportamento etc.) e que as outras aí se "traduzam", de certa maneira, direta e indireta, próxima ou longínqua.

Para contemplarmos algumas imagens e significações imaginárias explicitadas pelos indivíduos, obtidas através de entrevistas acerca do rural, fizemos uma incursão pelo socialhistórico goiano na perspectiva do imaginário social de Cornelius Castoriadis. Esta incursão teve como propósito obter um quadro de referência que nos permitisse cotejar o imaginário do turista rural. Ancoramos a exploração do imaginário rural do turista no imaginário social de Goiás, cuja sociedade, durante todo o século XIX e até bem recentemente, revestia-se de caráter quase exclusivamente rural.

Para obter este quadro de referência selecionamos algumas narrativas com o intuito de demonstrar que a sociedade goiana está impregnada de imagens que conferem um status ainda rural ao estado, contribuindo para que haja uma busca imagética do individuo pelo turismo rural. Em uma espécie de exercício de curadoria critica elaboramos alguns painéis narrativos onde 
contemplamos algumas imagens, algumas significações centrais do rural no social-histórico de Goiás.

Para a montagem desses painéis foram escolhidas quatro narrativas, em razão da centralidade do tema e da representatividade de seus autores. Os dois primeiros painéis se referem á relatos históricos que pretendem reconstituir o que de fato existiu, através de alguns autores, como Luiz Palacin $^{4}$ (1976) e Paulo Bertran ${ }^{5}$ (1978), os mais representativos em Goiás. Esses dois autores não se opõem, se complementam, na interpretação do que significou a sociedade agrária goiana tradicional: período de decadência ou de invenção de uma forma superior de convivência humana.

O terceiro painel mostra a criação de imagens do rural antigo pelo caminho da poesia, da instituição artística presente na obra Tropas e Boiadas, de Hugo de Carvalho ${ }^{6}$ Ramos (2006), coletânea de contos de inspiração sertaneja, publicado em 1917, que constituiu chave para ingressarmos no imaginário da sociedade rural goiana; entre o horror e a beleza da vida no sertão. Nesta narrativa a apreciação da ruralidade goiana não se resolve sob o prisma do verdadeiro em sua literalidade - sua verdade é do gênero alegórico-mítico, através do qual ás situações sociais e ás referências históricas encontram sentido no quadro da unidade e da solidariedade da vida. E nem do ponto de vista do bom e de suas interpretações como útil, honesto, moderno, desenvolvido. A beleza é o valor que prevalece. Nessa narrativa, o herói infeliz, o homem simples do campo, não se petrifica diante de sua existência desgraçada. Ele a transfigura na alegria de uma afirmação superior. Ele diz eternamente sim no sentimento da nostalgia do sertão.

O quarto painel trata do novo imaginário social em construção desde a Revolução de 1930 até a atualidade em Goiás. Tentamos mostrar no delineamento desta última narrativa alguns momentos, remissões e deslocamentos, no processo de superação de uma cultura rural e sua transformação em outra rural-urbana. A problemática da superação dessa sociedade nos conduziu à

\footnotetext{
${ }^{4}$ Luis Palacin - espanhol de nascimento e goiano por opção - foi padre da Companhia de Jesus, economista, filósofo, teólogo e professor de historia da Universidade Federal e Universidade Católica de Goiás. Padre Palacin, como era conhecido, foi pioneiro na investigação historiográfica de Goiás, deixando vários livros publicados. Dentre eles, Do sempre e do instante. Goiânia: Ed. Oriente, 1978; Fundação de Goiânia e desenvolvimento de Goiás. Goiânia: Oriente , 1976; História de Goiás (1722-1972): estrutura e e conjuntura numa capitalista de Minas. 6. ed. Goiânia: Ed. Oriente , 1972; Historia de Goiás em documentos: I Colônia. Goiânia: Ed. da UFG.

${ }^{5}$ Paulo Bertran foi professor em Brasília e Goiânia (UNB, UCG, UFG); especialista em contrução de casas de barro, introduzindo o conceito de Eco-História na moderna historiografia brasileira. Publicou vários artigos em jornais, revistas e publicações especializadas e livros importantes de Goiás e do Centro-Oeste tais como: Formação Econômica de Goiás. Goiânia: Ed. Oriente, 1978; História da Terra e do Homem no Planalto Central. Brasília, DF: Verano, 2000; Uma introdução à História do Centro-Oeste do Brasil: Goiânia: Ed da UCG, 1988.

${ }^{6}$ Hugo de Carvalho Ramos nasceu em 21 de maio de 1895, na cidade de Vila Boa, antiga capital do Estado de Goiás e faleceu em 12 de maio de 1921 no Rio de Janeiro. Iniciou sua carreira literária ainda bem jovem, com a publicação de artigos, contos e poemas. Tropas e Boiadas, seu único livro publicado, transcende à literatura pela visão antropológica do processo de povoamento do interior brasileiro. É uma das obras goianas mais aclamadas pela critica literária nacional.
} 
identificação dos fatores e dos processos que instauraram um novo estado de coisas que transformou o campo de Goiás e também as definições e imagens de rural. Emerge e vai-se consolidando um continuum rural urbano em que as relações entre cidade-campo se intensificam. Relações que segundo Raymond Williams (1989, p.19), constituem "uma história ativa e contínua (...) relações de idéias e experiências, mas também de alugueis e juros, situação e poder que se move em sentimentos e idéias através de uma rede de relacionamentos e decisões".

Após a montagem dos painéis recorremos á pesquisa empírica com indivíduos que buscam o campo para lazer e sociabilidade. Ela foi realizada em estabelecimentos turísticos de diferentes modalidades, localizados na Região Metropolitana de Goiânia (RMG). A escolha da RMG deve-se a estreita relação com a visão de continuum $^{7}$ rural-urbano, que coloca em conexão campo e cidade. Entrevistamos turistas acima de 30 anos de idade por verificar ser a frequência nos estabelecimentos de turismo rural, que visitamos em Goiás, constituídas predominantemente de famílias com crianças ou casais de meia idade.

\section{Retratos do rural}

\subsection{O rural de Goiás}

Através das narrativas vimos como a sociedade se institui e se transforma, como Goiás instaura seu mundo de significações por meio do que diz, do que é, do que quer, de suas prioridades. Pudemos perceber como a sociedade mostra, como ela vê seu passado, como quer construir seu futuro, o que considera uma vida boa etc., tendo sido possível a construção de categorias acerca do campo empírico narrado pelos entrevistados, que de alguma maneira foi imaginado. O imaginário efetivo já existe no "magma" social e os indivíduos de alguma maneira são tributários dele (CASTORIADIS, 1982).

Ao voltarmos à instituição da sociedade goiana tradicional, vimos está impregnada de imagens que conferem um status ainda rural ao estado. Há indícios que apontam para a reelaboração simbólica do rural tradicional como elemento integrante de uma identidade nova, plural, que sincretiza a fazenda e o shopping, o sertanejo e o peão de rodeio, o curral e a feira

\footnotetext{
${ }^{7}$ Essa visão permite compreender o rural e o urbano em suas especificidades, mas ao mesmo tempo os coloca em conexão. De acordo com Graziano da Silva \& Del Grossi (2006) o "novo rural” que está sendo gestado no Brasil com o fosso cravado entre cidade e campo, se faz sentir com a entrada de atividades que ultrapassam a agricultura e a pecuária como atividades tradicionais do espaço rural.
} 
agropecuária. Remete à simbologia anterior para inventar o presente, não sem associá-lo, às vezes, à imagem rural da sociedade goiana tradicional.

$\mathrm{Na}$ atualidade há emergência do novo imaginário social, que se faz acompanhar da transformação do quadro da infraestrutura material que lhe serve de suporte, mas que talvez não tenha produzido ainda narrativas que nos esclareçam suficientemente sobre suas significações sociais reelaboradas. Em especial, aquelas relativas ao novo contínuo rural-urbano em formação. Ou talvez essas narrativas já estejam presentes, e as mais significativas passem despercebidas, por as procurarmos com os critérios do ontem.

As tradições reinventadas no novo contexto do continuum rural-urbano - onde campo e cidade se colocam em conexão -, como as cavalhadas, o arroz com pequi, a pamonha, em que a sociabilidade goiana se atualiza que, permitem afirmar que se uma cultura foi superada, uma outra se formou na riqueza de seus húmus. Pode-se então levantar a hipótese da formação de uma cultura singular em Goiás, de uma identidade goiana, de uma "goianidade" 8 . Identidade múltipla, plural, contraditória, transversal, que associa as várias heranças e as várias matrizes de sua história em todas as épocas, que exprime os modos de ser do goiano e suas formas de co-pertencimento ao jeito de ser.

\subsection{Do campo imaginado ao campo comemorado}

O cotejamento com o imaginário social goiano se constituiu em chave mestra para o acesso ao imaginário rural do turista, sendo mister explicitar-se que o "meio natural" imaginado pelo turista distingui-se daquele do homem, melhor dizer, da sociedade ou da cultura tradicional rústica ou caipira. Até, senão sobretudo, porque os seus vínculos com esse meio, ou, mais radicalmente, na expressão de Castoriadis (1982, p. 399), com o "dado" ou "suporte natural”, são de uma toda outra ordem".

Na sociedade camponesa tradicional, como demonstra Antônio Candido (1971, p. 23-32), o vinculo do homem com o meio sensível é mais estreito, pois que é interagindo imediatamente com ele que o homem produz, concomitantemente, sua subsistência e sua vida social e cultural.

\footnotetext{
${ }^{8}$ A cultura local configurada sob a forma de "goianidade" para Freitas (2001, p. 183) é a "propriedade distintiva do goiano e de Goiás". Sabe-se que a goianidade provém de várias fontes e pode ser tratada a partir de diferentes dimensões. No entanto neste trabalho, pretendeu-se abordá-la do ponto de vista da dimensão simbólica que possibilita capturar um conjunto de diferentes imagens, destacando-se um de seus traços constitutivos: a ruralidade.
} 
Não é demais enfatizar, para maior clareza, com Castoriadis (1982, p. 399), que "o primeiro estrato natural" é ele mesmo imaginado ou "instituído", constituindo um "outro" da natureza. Ou seja, como diz Morin (2005c, p. 112) “A natureza não é unicamente o substrato "objetivo" da realidade antropossocial: é também um produto antropossocial. A cultura co-produz a natureza dando-lhe um rosto. A natureza existe antes de nós, fora de nós, mas sem nós".

Não é sem razão que o retorno ao rural em Goiás está associado á ideias construídas acerca da cultura e do cotidiano no campo: de pureza, de paz, de tranquilidade - condição que se acredita não mais existir nas cidades. As viagens empreendidas a hotéis-fazenda, pesque-pague e a restaurantes rurais, de certa maneira, prestam-se a saciar uma necessidade de volta às origens, de convívio com o natural - enriquecido em Goiás, com as peculiaridades do Cerrado - e, com a vida simples, embora, por vezes, quem visita esses espaços não encontre correspondência com as lembranças guardadas em sua memória ou que estão em seu imaginário de rural.

De acordo com os relatos, o campo como espaço de lazer, sociabilidade e vida saudável, transforma-se no exercício da "prática mágica e espontânea do espírito que sonha", nos termos de Edgar Morin, e no paraíso onírico das recordações do rural tradicional goiano.

\subsubsection{O campo imaginado}

O campo imaginado pelo turista, de acordo com os relatos, a natureza aparece em primeiro lugar. Por isso, ele parte em direção a ela como quem vai ao encontro do sagrado, que lhe proporciona paz, felicidade e liberdade. Há nessa viagem, certa dimensão religiosa, sagrada que o separa das coisas profanas, do cotidiano da vida urbana prosaica. E, no contato com "o chão sagrado" do espaço rural, ele executa o gesto de descalçar "os sapatos" da vida social e prática, para participar da força e do poder da natureza.

Qual é, pois, o rosto da natureza para o turista? Essa natureza aparece para o turista como "as árvores, ar puro, tudo o que a gente não encontra no meio urbano" diz Neiva. Um dos entrevistados, com idade acima de 70 anos, é mais expressivo e confessa: “eu gosto do campo. Hoje eu sinto quando aquela chuva molha a terra, chego, chego a sonhar com as fileirinhas de arroz, de feijão que você planta, que brota aquelas linhas, certinho. Eu chego a sonhar com isso".

Tranquilidade, paz, silêncio, sossego, descanso são os motivos que os turistas mais explicitam para sua ida ao campo. São essas significações que eles associam ao campo com mais frequência. É o que, por exemplo, exprime Márcia: “Eu vim pra cá, assim, procurando tranquilidade 
(...). Eu vim cá mais pra relaxar. Pra relaxar do movimento, vim para um lugar tranquilo. Acho que na fazenda é bem mais tranquilo". Essa ruptura com o "movimento", com a vida cotidiana é a condição mesma da expansão da consciência na contemplação.

\subsubsection{O campo contemplado}

Pude verificar que o contato com a natureza provoca deleite ${ }^{9}$. Há, de fato, verdadeira contemplação - olhar admirativo e afetuoso, em que mais se ama do que se conhece.

O que agrada aos sentidos, afinal, é uma das mais tradicionais definições do belo ${ }^{10}$. Iara relata que gosta de ficar ouvindo "o barulho das águas, das árvores...”. José Maria se encanta com “o verde da mata, o canto dos pássaros, o gado, o pasto. Tô vendo um pônei ali também, então, isso aí... também tô ouvindo uma galinha, tô ouvindo o barulho dum miquinho...".

A confissão de Neiva explicita as articulações e as continuidades da atitude contemplativa com seu objeto e com seus frutos. "Ah, eu gosto de ficar assim em paz, sem escutar barulho, bem tranquilo, bem relaxado. Assim... ver as águas, a tranquilidade mesmo”. Ela quase se unifica com o objeto contemplado, no esquecimento de si mesma. Sua paz é a tranquilidade das águas; a tranquilidade das águas é a paz.

Através dos relatos pude perceber que a vida no campo é vida poética. A atitude contemplativa, pelo menos incoativamente, também é vida poética. Mas, talvez, de uma forma mais receptiva, talvez mais passiva, em que o sujeito mais reflete a claridade de uma luz poderosa do que a produz ele próprio. Ainda que esse espelho e essa fonte se confundam em sua comunhão íntima.

Entendo a poesia nesse contexto como estado, talvez, mais predominantemente ativo, talvez de mais alegria e festa do que de harmonia e deslumbramento; talvez de mais satisfação e exaltação do que de fascínio e êxtase, recorrendo aqui às qualificações que Morin (2005, p. 132-140) associa a esses estados. Talvez, quem sabe, pode-se dizer que são "moradas", aposentos contíguos de um mesmo casarão encantado.

\footnotetext{
${ }^{9}$ Para maior compreensão do caráter estético da contemplação consultar Morin (2005, p. 132). Para este autor "A estética contemporânea é concebida não somente como uma característica própria da obra de arte, mas a partir do sentido original do termo, aisthétikos, de aisthanestrhai, "sentir". Trata-se de uma emoção, uma sensação de beleza, de admiração, de verdade e, no paroxismo, e sublime; aparece não somente nos espetáculos ou nas artes, entre os quais, evidentemente, a música, o canto, mas a dança, mas também nos odores, perfumes, gostos dos alimentos ou das bebidas; origina-se no encantamento diante do oceano, da montanha, do nascer do sol".

${ }^{10}$ Para esta discussão sobre o caráter estético da natureza nos fundamentamos em Plazaola, Juan S. Introducción a la estética: História, teoria, textos. Madrid: Biblioteca Cristianos, 1973, p. 358-360.
} 
O sentimento confessado por Lúcia, no espaço de lazer rural, nos permite melhor compreender do que se está a dizer: "é capaz mesmo... é como se Lúcia do dia a dia não existisse. Aqui é uma Lúcia moleca, uma Lúcia criança, uma Lúcia que consegue ver, assim, o pingo d’água e se maravilha com isso. Agora mesmo em cada árvore queria subir de novo como se fosse criança”.

A poesia talvez, é possível dizer, seja mais moleca, mais lúdica, mais serelepe do que contemplativa.

\subsubsection{O campo vivido}

O corte com o cotidiano é registrado pelos turistas nos diversos gestos com o que se despedem da veste social. Roselane gosta de "tirar o sapato, pé no chão, essas coisas". A fala de Valéria aponta que essa ruptura marca a entrada no mundo da descoberta, da dilatação da mente, próprios do estado poético: “Aqui a gente não tá preocupada, a gente vem à vontade, pra começar completamente à vontade, de chinelo, roupa confortável, no dia a dia... E junto do traje vem o espírito, que vai se abrindo para o que a gente vai encontrar por aqui, na realidade, aqui. Muito ar, né!, ar fresco, ar saudável, bichinho, que a gente não sabe o nome, mas sabe que vem da natureza...".

Erlane (acompanhada do marido) diz que o "rural é mais gostoso... bem-estar, respiração... Vim aqui ver uma planta que tem aqui e que é diferente, que ele (o marido) viu e eu não vi”. De novo o bem-estar, a descoberta que pode associar-se com o sentimento de Maria Fernanda, no Pesque-Pague, quanto ao encanto da simplicidade que liberta "a gente pode ficar tranquilo, a gente sente menos necessidade de cada coisa...".

No clima de boa vontade geral - quase unânime - do turista para com o campo, Irasmon confessa: "Eu vejo que as pessoas ficam mais livres, mais liberais, ou seja, chegam à felicidade".

\subsubsection{O Campo rememorado}

Vi que há um campo rememorado pelos turistas e regula-se muito mais pelos critérios da verossimilhança que pelos da verdade factual. A rememoração do campo é assim uma faceta do imaginário rural do turista. Recordar é, pois, dar uma forma simbólica, um sentido, uma significação atual à experiência passada. É abrir-se a interpretação da experiência passada para o que Cassirer (1997, p. 92) denomina "a terceira dimensão do tempo, a dimensão do futuro". A memória é sempre memória afetiva já que reorganiza poeticamente a experiência passada. 
Que lembranças têm os turistas de sua vivência rural pretérita? Que significação dão eles a essa experiência compartilhada do campo?

Uma primeira observação se impõe. Ainda que 17 dos 27 entrevistados se identifiquem como de origem rural, quase ninguém associa suas lembranças ao trabalho, aos processos produtivos do campo. A pouca evocação espontânea dos processos produtivos do campo pode ser relacionada também a rápida transformação do campo goiano ${ }^{11}$. Segundo senhor Waldomiro, "hoje a pessoa faz é comprar na cidade para comer na roça. Não traz da roça para comer na cidade, não. Quando muito traz da roça uma laranjinha...”.

A vida no campo, rememorada, os turistas associam qualidades de caráter e valores humanos positivos. Alegria, simplicidade, saúde, solidariedade e amizade são alguns deles. Segundo Seu Waldomiro, na roça "ali, ó, o pai criava dez filho, sustentava tudo, criou tudo, sabe, cada homem sadio, direito, tem gente boa (...). Na roça era bom demais... Tinha escolinha, lá na roça você estudava, você criava seu filho. Eu conheço gente que criou terceira geração numa fazenda só".

É nas lembranças das festas que os valores da roça - imaginados - mais se explicitam. Roselane relembra as festas de casamento: "era aquelas festas que matava cinco bois mais ou menos; era gente demais (...) vinha gente de tudo ali, os vizinhos (...)". Luiz apresenta a vida passada no campo como vida festiva, um idílio num mundo simples e natural:

No domingo a gente saía, juntava os amigos, sempre tinha uma vela na igreja, tinha um leilão que a gente fazia (...) tinha um leilão de frango, leilão de leitão. (...) Eu lembro a queima de Judas que tinha também lá na fazenda. Ah, era muito boa, o povo tudo aprontava pra ir na festa naquela fazenda que ia ter o Judas e todo mundo ia bater, espancar ele, pendurar e depois botar fogo nele, explodir e depois, assim a gente saía.

O rural transformado projeta cada vez mais linhas de continuidade entre campo e cidade, mas, mesmo assim, ainda continua sendo o paraíso das recordações da infância. Maria Fernanda relembra que "ia tomar banho de córrego com as primas. Não tinha chuveiro na casa, era normal mesmo o banho de córrego no final da tarde".

De fato, a experiência adulta dos turistas tempera a visão infantil, paradisíaca do campo. Convidados a se manifestarem sobre a eventualidade da troca da vida urbana atual por uma ida ou

\footnotetext{
${ }^{11}$ Há emergência de um novo rural em Goiás, que se consolida e que projeta linhas de continuidade entre campo e cidade, que chegam a desorientar o turista. Passou muito celeremente da fazenda autárquica, auto-suficiente, para uma situação em que o alimento parece emanar miraculosamente dos armazéns e dos empórios da cidade, em direção ao campo, que em vez de comida passou a produzir commodities.
} 
um retorno à vida rural, eles deixam aflorar a memória social dos constrangimentos e dos aspectos da vida do campo, bem como os encantos e as comodidades da vida urbana. Muitos dos relatos dão conta de que a bica d'água do banho era de água fria, que ela substitui o banheiro que faltava e que é lá que se tinha de lavar a louça. Que o lampião romântico significa também falta de eletricidade.

Os turistas querem o campo como "um ponto de refúgio" (Roselane), "refrescar um pouco a cabeça" (Lúcia), "reviver" (Lara), "um pouquinho ver as origens do campo (Lúcia), mas não o veem como alternativa de vida. Eles têm consciência de seu enraizamento e de seus compromissos urbanos. "Minha profissão é meio assim complicada, não bate com a vida no campo" diz José Maria. "Viver na zona rural, talvez pela condição do mundo moderno, das condições mesmo de trabalho, ficaria muito difícil" (Iara). Mas não é só isso. Eles também apreciam as vantagens e os valores da vida urbana: "a comodidade (Marcelo), a parabólica... a comunicação externa” (Leônia), “o cinema... contato... on-line... internet” (Maria Fernanda), "muita gente. Isolamento, eu não gosto" (Erlane).

O indivíduo ao buscar o campo como refúgio, o faz com a consciência que "tem que ter um equilíbrio" (Márcia) entre a vida rural e a vida urbana. "Associar os dois"12 como gostaria Maria Fernanda.

\subsubsection{O campo venerado}

A dimensão religiosa está presente na busca do campo pelo turista. Ele o representa para si mesmo como coisa sagrada, separada das coisas profanas, do cotidiano da vida prosaica. Não foi minha intenção procurar ou estabelecer homologia entre os elementos estruturais e suas significações nos processos de turismo e de peregrinação. Uma aproximação, no entanto, nos parece fecunda para nosso objetivo de desvelar o imaginário rural do turista.

Posso afirmar que o turista rural é também um peregrino ${ }^{13}$; enquanto se desloca, põe-se em movimento, em direção ao espaço sagrado. A primeira epifania deste sagrado se faz, pela visão. As pessoas querem, em primeiro lugar, observar, ver. Foi por meio da visão que eles se iluminaram, conforme testemunharam. O sagrado revelou-se para eles.

\footnotetext{
${ }^{12}$ Não é arbitrário afirmar que essa alternância proporciona ao turista os benefícios que Morin (1984, p. 258) apontara nos anos 70 para a "dupla vida urbana-neo-arcaica": "o relaxamento fora do ecossistema urbano e o ganha-pão neste ecossistema (...) um certo bem-estar na alternância das duas "culturas", ou mesmo dos dois cultos: o culto da vida urbana moderna, da sua intensidade e das suas liberdades, e o culto da vida rústica, com a presença tranqüilizadora da Physis e do Arque".

${ }^{13}$ MacCannel, citado por Steil (2002, p. 59) aponta "um processo de sacralização no turismo que seria semelhante ao que acontece no campo religioso, fazendo com que determinados artefatos, naturais ou culturais, sejam erigidos como objeto de veneração e respeito".
} 
Mas o campo é também sua casa por substituição, a morada que lhes acolhe, sossega, tranquiliza, aquieta, consola. Que lhes revigora. Onde eles se encontram em paz, felizes e em liberdade: a terra, a natureza. Instintivamente, eles parecem saber, como enfatiza Morin (2005, p. 451), que "precisamos então reencontrar a nossa Natureza...".

Refugiando-se da cidade, para a natureza sagrada, os turistas se dirigem: Irasmon, para "sair da capital, da cidade, do barulho do dia a dia". Márcia: "Pra relaxar, pra relaxar do movimento". Lívia: "Devido ao descanso, ao sossego... Vim em busca disso". Carlos Alberto quer "repor as energias pra começar segunda-feira tranquilo. Porque da Terra emana força e poder”. Iara valoriza "O contato com a terra. Acho que é importante. Pisar na terra". Roselane procura "o contato direto com a natureza, tirar o sapato, pé no chão”.

O contato com a terra, com chão sagrado, para o qual o turista se prepara pelo rito de tirar os sapatos da vida social e prática, o faz participante da força e do poder da natureza. Atualiza suas esperanças. Ressignifica sua vida.

Esse encontro com o "chão sagrado" é efêmero, a permanência no espaço de lazer não vai além do final de semana. Essas condições não são totalmente propícias à emergência de uma sociabilidade mais convivial, que afinidades, cumplicidades, trocas de emoções criem uma “comunhão". Um "nós" não chega a se constituir. Marta lamenta não encontrar a sociabilidade do rural antigo, em que "se você passa, chama pra conversar, tomar um cafezinho naquela xicrinha de louça, né? 'não, vem cá, toma um cafezinho aqui’. Ah!... Então era gostoso. Quantas vezes a gente ia pra fazenda e o pessoal chamava: 'não, vem aqui, vamos fumar um cigarrinho'... Hoje em dia não tem mais isso, né?"”.

Márcia estranha que ninguém fale com os outros, porque "aqui, por exemplo, tem quiosque perto, mas ninguém conversa com ninguém”. Isto, porém, não a incomoda, porque “vim pra cá esperando tranqüilidade, não assim, com o intuito de às vezes confraternizar com a pessoa ao lado. Eu quero um lugar tranqüilo”. Kétina pensa como Márcia e não gostaria de repetir a sociabilidade do rural de antigamente: “Ah!... Acho que não sei. Não seriam as mesmas pessoas; eu acho que não, não. Não, não... Aquilo lá é tradição de família”.

Verifiquei nas falas das pessoas a visita a estabelecimentos rurais não é feita em conjunto com outros peregrinos, diferentemente do que se faz nas peregrinações religiosas, e, em regra, esse turista dispõe de pouco tempo. Em decorrência disso, a sociabilidade torna-se breve, a te mesmo para a celebração conjunta com outros que não os familiares. 


\subsubsection{O campo comemorado}

O "contato" com a natureza que, temos visto, expressa a busca imaginária pelo campo, encontra seu coroamento na comunhão com ela pelo ritual da refeição. O turista que veio para o campo para "repor as energias" (Carlos Alberto), agora se refaz, nutrindo-se da mãe natureza.

O filho que volta comemora comendo. Nessa operação, o turista emprega todos os sentidos: os da alegria e os do gozo ${ }^{14}$. Os mais puros e espirituais - a visão, que ele também utilizou na contemplação da paisagem, das águas e das plantas -, a audição, com que ele ouviu o canto dos pássaros, o sussurrar do vento a balouçar os galhos e as folhas - e os mais apetitivos e sensuais cheiro e, mais ainda, o tato e o paladar.

Por associação, alguns alimentos evocaram o "cheirinho", o gosto da comida do rural tradicional, preparada no fogão à lenha. O "fogão caipira" conduziu Amauri a associar a comida da Santa Branca com a fazenda. O mesmo aconteceu com Neiva, para quem "o cheirinho me faz recordar a fazenda, a casa da minha avó... minha avó até hoje tem fogão a lenha...” Para Erlane, “o cheirinho, né, do tempero, da fumaça" também acrescenta emoção ao "arrozinho com carne" que comeu na Villa Cerrado.

De todos os alimentos citados nos relatos, o pequi é o alimento mais apreciado pelos turistas. Diz Luiz Carlos Queiroz: “Adoro pequi, nossa senhora!... arroz com pequi, tudo com pequi é maravilhoso". Érica tem a mesma opinião. Ela não foi para o Villa Cerrado para comer, mas comeu "arroz com pequi, frango com pequi, tudo com pequi é maravilhoso".

Marta foi para o Villa Colonial pra comer: "Eu comi frango caipira, o arroz, o pequi. Eu adoro pequi. (...) Eu gosto da comida típica, goiana mesmo”. José Maria foi para o banana Menina esperando encontrar: "Em primeiro lugar... uma boa, uma ótima comida caseira. Aquela comida típica” e lá comeu "a galinha... é, o arroz com pequi, leitoa à pururuca".

O pequi, humilde fruto das cariocaráceas, é o alimento mais apreciado pelos turistas. No turismo rural ele adquire certa sacralidade simbólica, tornando-se quase um totem, capaz de unir, de congregar os membros da comunidade que o transformou em emblema da goianidade. $\mathrm{O}$ pequi, por exemplo, talvez se possa dizer sem sacrilégio, que sua virtude, sua santidade seja imaginária. Se ele se constitui o prato da goianidade.

\footnotetext{
${ }^{14}$ Sobre a hierarquia dos sentidos, conforme algumas escolas filosóficas e estéticas, fundamentamo-nos em Plazaola, Juan S. Introducción a la Estética: historia, teoria, textos. Madrid: Biblioteca de Autores Cristianos, 1973. p. 309-310; 317; 369-371.
} 
A sacralidade desse alimento provém de seu caráter simbólico, do fato de unir, de congregar os membros da comunidade imaginada que o escolheu, que o transformou em totem e emblema, a qual ele exprime. Em última análise, o que se comunga com o pequi é uma ideia, uma crença. O que se reitera é o sentimento de pertencer a este grupo. O organismo que se revivifica, de que se refaz a substância é, em último lugar e principalmente a família, com a qual se significa querer permanecer unido, indo comer, juntos, no restaurante rural.

É certo que o ato de comer, por si rotineiro e profano, adquire caráter de celebração em razão da sacralidade do lugar - o campo - e do tempo - o descanso ritual dos dias de não negócio (feriados e finais de semana) - em que se realiza. Simbolicamente, celebra-se o encontro com a natureza pelo ritual da refeição, momento comemorado, em que se comem pratos típicos da culinária goiana, como arroz com pequi; galinhada (arroz com frango), guariroba e outros. Neiva, inclusive, ressalta que gosta de comida caseira e na Pousada, onde a entrevistei, diz que comeu comida "simples... bem normal mesmo, que significa saúde, saudável, do campo", comeu "frango de caldo, arroz".

\section{Considerações finais}

Viu-se que a volta ao rural goiano está prenhe de símbolos originários da tradição rural de Goiás, embora, na atualidade de forma ressignificada, símbolo de um passado agregado á memória coletiva. De forma sintética, procuramos mostrar que os traços que ajudaram a dar uma feição ao estado de Goiás convidam imageticamente o indivíduo a buscar o campo como lazer e espaço de sociabilidade. Há uma convivência entre os aspectos da cultura e modos de vida, construtores simbólicos da identidade regional que hoje se reelaboram no rural continnum.

Artigo submetido em 01/06/2013 e aceito em 28/08/2013.

\section{Referências}

BERTRAN, Paulo. Formação econômica de Goiás. Goiânia: Oriente, 1978 (Título I).

CASSIRER, Ernst. Antropologia filosófica: ensaio sobre o homem. 2. ed. São Paulo: Mestre Jou, 1997.

CASTORIADIS, Cornelius. A instituição imaginária da sociedade. Rio de Janeiro: Paz e Terra, 1982. (Coleção Rumos da Cultura Moderna, 52). 
CANDIDO, Antonio. Os parceiros do Rio Bonito: estudo sobre o caipira paulista e a transformação dos seus meios de vida. 2. ed. São Paulo: Duas Cidades, 1971.

FREITAS, Lena Castelo Branco Ferreira de. Goiás e Goianidade. Revista da Aflag - da Academia Feminina de Letras e Artes de Goiás, Goiânia, n. 1, p. 183-191, 2001.

SILVA, José Graziano da; GROSSI, Mauro Eduardo Del. O novo rural brasileiro: uma atualização para 1992-98. Campinas, 2006. Disponível em <http://www.econunicamp.br>. Acesso em: 5 abr. 2007.

MORIN, Edgar; NAIR, Sami. Uma política de civilização. Lisboa: Instituto Piaget, 1997 (Coleção Economia e Política).

MORIN, Edgar. O Método 5: a humanidade da humanidade. 3. ed. Porto Alegre: Sulina, 2005.

MORIN, Edgar. Sociologia: a sociologia do microssocial ao macroplanetário. Lisboa: EuropaAmérica, 1984.

MORIN, Edgar. O Método 1: a natureza da natureza. 2. ed. Porto Alegre: Sulina, 2005.

MORIN, Edgar. O Método 2: a vida da vida. 3. ed. Porto Alegre: Sulina, 2005.

MORIN, Edgar. O cinema e o homem imaginário: ensaio de antropologia. Lisboa: Grande Plano, 1997.

PALACÍN, Luis. Goiás: 1722-1822. 2. ed. Goiânia: Oriente, 1972.

PLAZAOLA, Juan S. Introducción a la estética: história, teoria, textos. Madrid: Biblioteca Cristianos, 1973.

STEIL, Carlos Alberto. O turismo como objeto de estudos no campo das ciências sociais. In: RIEDL, Mário; ALMEIDA, Joaquim Anécio; VIANA, Andyara Lima Barbosa (Org.). Turismo rural: tendências e sustentabilidade. Santa Cruz do Sul: Edunisc, 2002. p. 51-80.

WILLIAMS, Raymond. O campo e a cidade: na história e na literatura. São Paulo: Companhia das Letras, 1989. 